\title{
MARKETING, POLÍTICAS DE CRÉDITO E INADIMPLÊNCIA. VENDER BEM E EVITAR O MAU PAGADOR: UM DESAFIO PERMANENTE
}

\author{
MARKETING, CREDIT POLICY AND FAILURE. \\ A GOOD SELLING AND AVOID BAD CREDIT: A CONTINUING CHALLENGE
}

\section{Istvan Karoly Kasznar}

\section{RESUMO:}

O presente artigo mostra que a inadimplência voltou a crescer após a grande crise mundial gerada pela incapacidade de se saldarem as cédulas hipotecárias nos Estados Unidos da América. No Brasil sucedeu o mesmo e isto possui sérias conseqüências sobre o mercado de crédito, a concessão de novos empréstimos, o spread ou margem de retorno bancário, as taxas de juros e as vendas a crédito das empresas. Portanto, existe uma forte e significativa correlação, no caso negativa, entre vendas e elevação do nível de inadimplência. Mostra o autor que existem variáveis macroeconômicas relevantes para explicar a inadimplência, e que elas são as mesmas no Brasil e no exterior. De fato, indicam a inadimplência o desaquecimento econômico ou a perda e queda do PIB; o aumento do desemprego; a diminuição do rendimento médio do trabalhador; e o aumento da carga fiscal, entre outros. 0 artigo indica e debate estas variáveis e alerta a sua relevância também para a geração adequada de políticas de marketing e vendas.

\begin{abstract}
:
This article presents problems related to insolvency and personal financial distress. It grew once more, after the so called subprime market north-american crisis all around the world and in Brazil as well. As a wave-effect, this crisis presents serious consequences on credit markets, new loan supply by bankers, the level of spread or banks rate of return, interest rates and sales through the impulse given by credits to people and enterprises. Otherwise, there exists a strong and significant negative correlation between sales and a growth in the level of credit delinquency. The author shows that there exist relevant macroeconomic variables to explain the level of insolvency and financial distress, and they seem to be similar in Brazil, when compared to other countries. De facto, are to be considered recessions and output reductions because of economic crisis; unemployment growth; the diminution of average wages; and the fiscal burden growth, among others. The article indicates and debates several aspects of these variables and promotes the attention to its relevance as well as to the adequate generation of marketing and sales policies.
\end{abstract}




\section{INTRODUÇÃO}

Formar mercado, atuar no mercado e conquistar inúmeros clientes, para vender o máximo, tem sido o objeto contínuo e obsessivo de numerosas organizações.

Contudo, nem sempre vender o máximo é o ideal ou mais recomendado. Existem restrições importantes às vendas empresariais, que a área de Marketing precisa apreciar e entre elas se destaca a qualidade de bom ou mau pagador dos clientes.

Neste artigo estuda-se a inadimplência, como uma limitante de vendas e que há de ser considerada per se, como uma séria limitante da meta "vender o máximo". Nos tempos atuais e pelos próximos anos, de menor crescimento, será relevante e determinante saber a quem dar crédito e definir quem pagará de volta o empréstimo concedido, para que bancos e empresas encontrem resultados realmente sólidos para si.

\section{DEFINIÇÕES DE INADIMPLÊNCIA, INSOLVÊNCIA, CONCORDATA, BANCARROTA E FALÊNCIA.}

Não há uma definição única, consentânea e definitiva, sobre inadimplência. Conforme a definição "oficial", uma pessoa é considerada estar insolvente se é incapaz de pagar as suas dívidas no valor, nas especificidades e quando elas vencem, o que implica em atrasos e constrangimentos de pagamento (em: Consumer Wiki).

A conceituação de inadimplência é fornecida por Alberto Borges Matias como "o volume das dívidas com 15 a 90 dias de atraso sobre o volume total de crédito". A insolvência é diferente, porquanto entendida como "o volume de dívida com atraso acima de 90 dias em relação ao crédito total disponibilizado" (Financeiro; n. 53; ano 6).

As dívidas, logo posições passivas e sobre as quais corresponde um direito de cobrança por parte das financeiras e bancos, na ótica das pessoas físicas ou indivíduos, correspondem a valores contratados em cheque especial; crédito pessoal; financiamento de veículos, imóveis e eletrodomésticos; cartão de crédito e para a compra de bens variados.

Em relação às pessoas jurídicas, ou empresas, a inadimplência e a insolvência quando ocorrem se registram, sobretudo, com a assunção de dívidas destinadas à aquisição de bens, como veículos, imóveis e eletrodomésticos; operações de vendor; importações; hot money; desconto de notas promissórias e duplicatas; conta garantida; financiamento ao capital de giro (FCG) e outras operações ligadas a crédito.

O Banco Central do Brasil define a Inadimplência como a que acontece quando se comprovam "atrasos superiores a noventa dias", isto é, três meses, ao realizar análise sobre provisões e baixas contábeis líquidas no cenário internacional, com destaque para os Estados Unidos da América, país onde a quebra financeira das famílias entre 2007 e 2008, levou à crise do mercado subprime, com execução recorde de hipotecas, a maior da história dos EUA, após o craque da Bolsa de Nova Iorque em 1929 e sua conseqüente Grande Depressão dos anos 1930 (em: Relatório de Estabilidade Financeira; página 19;Maio 2008).

\section{O MERCADO DE CRÉDITO NO BRASIL: ELEMENTOS GERAIS E DA PESSOA FÍSICA}

Existe uma relação direta e positiva entre crescimento e desenvolvimento econômico, e volume de oferta de crédito financeiro.

Ofertar crédito livre a taxas de juros nominais e reais baixas sustentadas por uma política 
monetária, fiscal e cambial disciplinada e macroeconomicamente estabilizadora, é fundamental para o adequado controle dos orçamentos públicos e domésticos e gerar a expansão ordenada do consumo e do investimento agregados.

Quando a dívida mobiliária interna pública é diminuta e a arrecadação pública de impostos suplanta ou iguala as despesas governamentais, a pressão pela demanda por dinheiro e crédito pelo Tesouro cai e isto permite que a juros mais baixos se possa ofertar mais crédito livre, para as famílias e a iniciativa privada.

Portanto, concorrem pelo crédito disponível os agentes econômicos privados e públicos. Ao sinal de déficits crescentes no setor público, a taxa de juros tende a subir o que encarece o custo dos empréstimos, logo do mercado de crédito. Enquanto as famílias revêem sua posição orçamentária, os governos tendem a aumentar sua disciplina fiscal ou, relaxados, mantem a demanda por crédito, confiantes na arrecadação futura de impostos e no aumento da carga fiscal.

À luz destes elementos e fatos, na perspectiva brasileira, pode-se perceber que o mercado de crédito é fortemente direcionado pelas demandas e situações orçamentárias do Estado, que mediante o giro da dívida pública atrai para si e força a vinda das poupanças. 0 crédito que sobra, livre, torna-se caro, com taxas de juros reais elevadas, que contraem a demanda por crédito. Resulta então uma proporção relativamente pequena de créditos livres ao setor privado / PIB e relativamente elevada de créditos direcionados mediante aplicação em títulos públicos / PIB.

Em 1997, ano no qual os benefícios da sólida disciplina monetária se faziam sentir sob os auspícios do Plano Real, a taxa de inflação medida pelo IGP-M da Fundação Getúlio Vargas registrou 7,74\%, com tendência de baixa, para 1,78\% em 1998. 0 Produto Interno Bruto a preços correntes (PIB) atingiu R\$ 939 bilhões em 1997 e registrou sobre 1996 um crescimento real de 3,38\%. Os empréstimos do sistema financeiro (ESF) segundo o Banco Central do Brasil registraram um saldo em fim de período (dezembro) de $\mathrm{R} \$ 265,6$ bilhões em 1997. E a dívida líquida do setor público (DLSP) em 1998 registrava o montante de $\mathrm{R} \$ 388,7$ bilhões.

A dívida pública, reduzida mediante artifícios que incluíram a desconsideração da inflação na remuneração de títulos públicos em 1990, relacionada ao PIB em 1998, apresentava um coeficiente DLSP / PIB de 39,68\%. Em vez de afirmar que fosse baixa e controlada, mais adequado seria entender que era relativamente baixa em função das medidas do Plano Collor do ano 1990, que seqüestrou por 18 meses significativa parte dos ativos financeiros do país. Contudo, no ano seguinte, em 1999 a DLSP pulava firmemente para R\$ 516,5 bilhões, aumentando a relação DLSP / PIB para 52,77\%, numa demonstração de que a autoridade monetária sugaria o dinheiro do mercado, elevando as taxas de juros para reafirmar sua vontade de combater a inflação, e financiaria a dívida e o déficit do setor público às custas da retração do mercado de crédito livre, privado e por conseguinte das famílias.

Neste ambiente dos anos 1999 / 2002 é bem patente que enquanto retoma o endividamento público na forma de emissões de títulos públicos em relação ao PIB, gerando um indicador DLSP / PIB de 52,86\% no ano 2000 e com alta para 59,61\% em 2002, cai o crédito livre de tal forma que a relação ESF / PIB de 1999, com 26,95\%, cai para 25,6\% em 2002.

O efeito substituição e a preferência do governo no período é revelador: aumentar a dívida pública para crescer, lastreada na emissão de títulos públicos, cujo montante substituiria a 
divida externa pública e permitiria maior controle sobre os agregados monetários, permitindo um mais eficaz combate endógeno à inflação doméstica. Por outro lado, a poupança forçada e dirigida à estabilização das contas públicas acarretaria a redução drástica da demanda por créditos privados e tornaria as taxas de crescimento pequenas, tímidas, entre $1 \%$ e 3\%, como sucedeu efetivamente.

De 2003 em diante a disciplina fiscal e a política monetária se revelaram mais ortodoxas e firmes. 0 controle das contas públicas ganhou a ajuda da LRF - Lei de Responsabilidade Fiscal e a preocupação em ficar dentro de metas fiscais pré-estabelecidas confirmaram-se como política pública. As vantagens de tais medidas se fizeram sentir rapidamente, de tal forma que a relação DLSP / PIB caiu do recorde de 59,61\% do ano 2002, para 44,96\% em 2007, pari passu.

Em que pese a retomada da inflação em fins de 2007 e seu combate mediante a elevação das taxas de juros e controles monetários com aumento da base monetária, no período 2003 / 2007 configura-se nitidamente uma nova fase, de retomada e crescimento do volume de crédito concedido à livre iniciativa, no país.

Deste modo, a expansão de crédito saltou de 24,61\% em 2003, ano de combate a um IGP-M que mede a inflação brasileira com acuidade, de 25,2\% em 2002, para a relação ESF / PIB de 36,59\% no ano 2007. Esta evolução configura para o Brasil e seu mercado de crédito, no segmento estudado do consignado, um desempenho marcante, vigoroso e auspicioso.

Contudo, ele não vem apenas com loros e sinais de ganhos. Neste meio expansivo de crédito, o risco falimentar e inadimplente das pessoas físicas e jurídicas aumentou.

Nem toda a comunidade estava habituada a tomar crédito e a orçar corretamente seus gastos. Como conseqüência, os índices de inadimplência mereceram e hão de receber mais atenção analítica, pois quanto mais crédito se concede; quanto maior é a relação ESF / PIB, maior é o risco de emprestar em excesso, mal e gerar problemas nos intermediários financeiros.

A inadimplência há de ser vigiada e acompanhada de perto, para que se evitem graus excessivos de endividamento, cujo desfecho final é a desgastante renegociação de

dívidas, a retração do consumidor e do sistema de crédito e o clima de desconfiança em relação ao bom funcionamento das instituições.

A crise norte-americana de 2007 em diante, culminando na parada literal do mercado de crédito em setembro de 2008, em função dos abusos cometidos na expansão do crédito imobiliário, da geração de hipotecas podres subprime, evidencia que existe um limite para a oferta de créditos e quando ele é ultrapassado, põe em crise até mesmo o mais poderoso sistema econômico.

Antes que ocorram abusos no mercado de crédito brasileiro, satisfeito e mais desestressado de 2004 em diante, é importante que medidas de autoregulação do mercado se implantem, severas e disciplinadas, para evitarem-se inadimplementos e falências futuras, cujo desfecho aumenta custos e desgastes e pode pôr em risco o crescimento e o desenvolvimento de longo prazo.

Por conta da inflação crônica dos anos 70, 80 e 90, o brasileiro se viu sacrificado a pagar em prazos curtos significativa parte de suas dívidas e o mercado de crédito encurtou prazos. 
Neste início de terceiro milênio, a estabilidade econômica e o combate à inflação bem sucedido permitem que se volte à concessão de prazos mais longos e dilatados, para o pagamento de dívidas comerciais e financeiras. Os bancos e as financeiras respondem com rapidez a este aumento de eficiência no sistema econômico e não se fazem de rogados: oferecem maiores prazos, que fazem parte das condições facilitadoras da política de concessão de crédito.

O efeito desta dilatação é evidente: aumenta a demanda por créditos na economia.

Por outro lado, existem ao menos dois perigos, duas armadilhas, que o credor e o devedor juntos, de preferência, deveriam analisar. Prazos mais longos implicam em crescente diminuição da capacidade de antevisão do que sucederá em longo prazo. E prazos mais generosos fazem com que produtos como carros, motos, tratores, aviões e imóveis se depreciem em proporção maior, no decurso do tempo. Logo, os riscos do crédito sobem e as garantias reais podem ter e assumir um valor irrisível, em comparação com as dívidas existentes.

Dosar, calibrar adequadamente estes paradoxos, do prazo longo atraente para negócios, com os riscos ascendentes é papel tanto de tomadores, quanto de credores. $\mathrm{O}$ erro, a falta de se dar limite específico a operações de crédito, por dilatação excessiva das operações, pode elevar os níveis de inadimplência.

E isto, naturalmente, é perigoso para as financeiras e os bancos. Então, o sistema há de saber se regular, aprendendo a avançar na questão dos prazos, mas com medidas prudenciais oportunas e atinentes ao assunto.

\section{A FATIA DO MERCADO DE CRÉDITO INSOLVENTE}

O que importa é o crédito sadio, solvente, que se renova e cresce, para aumentar o consumo e o investimento agregados e como efeito cadeia o produto da nação.

Contudo, é de se esperar que exista uma margem de erro na concessão de créditos e uma parte dela não seja paga, representando os atrasados, a inadimplência e podendo levar em casos extremos à falência dos tomadores.

Pelos efeitos nefastos da inadimplência e da falência, que afasta os agentes econômicos do mercado, retrai a demanda, estigmatiza o endividado na sociedade e efeitos afins, é preciso disciplinar e orientar o mercado, o consumidor e os intermediários financeiros, para que se evite e, sobretudo minimize a bancarrota. Neste sentido, enfatiza-se que mais vale aumentar a qualidade e a quantidade das medidas precaucionais e prudenciais, antecedentes do desastre dos inadimplementos crônicos e volumosos, que criar após a devastação gerada por grandes crises econômicas e recessões, no rescaldo entre as cinzas da morte por falência, medidas curativas de efeitos duvidosos. 
GRÁFICO 1: Concessão de Crédito por segmento de atividade econômica mês de Setembro de

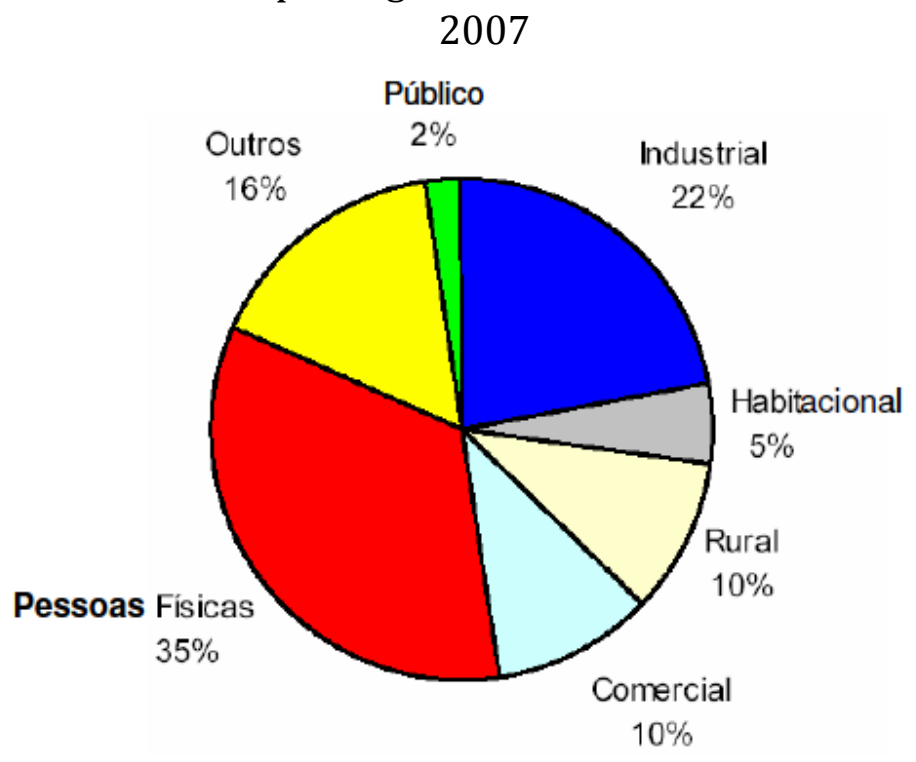

Fonte: de dados básicos: BCB

QUADRO 1: Principais modalidades de crédito - pessoa jurídica

\begin{tabular}{|c|c|c|c|c|}
\hline \multirow[t]{2}{*}{ Modalidade de crédito } & \multicolumn{2}{|l|}{2006} & \multicolumn{2}{|l|}{2007} \\
\hline & Jun & Dez & Jun & Dez \\
\hline Pessoa jurídica - Total & 1,9 & 1,9 & 1,7 & 1,3 \\
\hline Conta garantida & 3,1 & 3,7 & 3,2 & 2,7 \\
\hline Capital de giro & 2,2 & 2,0 & 1,7 & 1,6 \\
\hline Desconto de títulos e cheques & 4,0 & 3,5 & 3,2 & 2,6 \\
\hline Financiamento de veículos & 3,3 & 3,0 & 2,2 & 1,9 \\
\hline Financiamento de projetos & 1,3 & 1,0 & 0,8 & 0,5 \\
\hline BNDES (financ. direto) & 0,6 & 0,9 & 0,2 & 0,1 \\
\hline Arrendamento financeiro & 1,6 & 1,5 & 1,4 & 1,1 \\
\hline Imobiliário & 2,2 & 1,8 & 1,5 & 0,9 \\
\hline Rural e agroindustrial & 1,1 & 1,4 & 1,3 & 1,0 \\
\hline Comércio exterior & 0,6 & 0,4 & 0,5 & 0,2 \\
\hline Demais tipos de créditos & 2,4 & 2,7 & 2,7 & 2,2 \\
\hline
\end{tabular}

Fonte: Relatório de Estabilidade Financeira / Maio de 2008 - Banco Central do Brasil 
QUADR0 2: Inadimplência versus provisão constituída $\left(^{*}\right)$

\begin{tabular}{|c|c|c|c|c|}
\hline \multirow[t]{3}{*}{ Discriminaçäo } & \multicolumn{4}{|l|}{2007} \\
\hline & \multicolumn{2}{|l|}{ Jun } & \multicolumn{2}{|l|}{ Dez } \\
\hline & $\begin{array}{l}\text { Inadim- } \\
\text { plência }\end{array}$ & $\begin{array}{l}\text { Provisão } \\
\text { constituifa }\end{array}$ & $\begin{array}{l}\text { Inadim- } \\
\text { plência }\end{array}$ & $\begin{array}{l}\text { Provisäo } \\
\text { constituída }\end{array}$ \\
\hline Total do SFN & 3,8 & 6,3 & 3,4 & 5,8 \\
\hline \multicolumn{5}{|l|}{ Bancário } \\
\hline \multicolumn{5}{|l|}{ Consolidado } \\
\hline bancário I & 4,2 & 6,5 & 3,8 & 5,9 \\
\hline \multicolumn{5}{|l|}{ Bancos } \\
\hline públicos & 3,9 & 8,0 & 3,5 & 7,5 \\
\hline \multicolumn{5}{|l|}{ privados } \\
\hline nacionais & 4,3 & 6,2 & 3,7 & 5,4 \\
\hline estrangeiros & 4,4 & 5,1 & 4,3 & 5,0 \\
\hline bancário II & 0,9 & 4,8 & 0,9 & 4,8 \\
\hline bancário III & 2,6 & 5,0 & 2,2 & 4,7 \\
\hline Näo-bancário & 8,4 & 10,8 & 7,6 & 9,6 \\
\hline
\end{tabular}

(*)Comparação entre o percentual de inadimplência e o percentual de provisão constituída sobre o total das operações de crédito.

Fonte: Relatório de Estabilidade Financeira / Maio de 2008 - Banco Central do Brasil

0 quadro 2 anterior revela a inadimplência e a provisão constituída para fazer face a problemas eventuais de inadimplência empresarial e da pessoa física. É importante manter provisões bem elevadas, para que exista capacidade de cobertura de perdas eventuais e não se venha a estressar a tesouraria e a situação estrutural das finanças bancárias e financiarias.

O contraponto está no rendimento da provisão. Provisões altas são desejáveis, porque resguardam contra perdas. Podem não apresentar rendimentos significativos, pois as aplicações a elas associadas hão de preservar a segurança, a liquidez e títulos com essas características em geral fornecem rendimentos baixos.

Por outro lado, dispor de menores provisões significa dispor de mais dinheiro e crédito para ofertar no mercado, a taxas de juros bem mais atraentes para os credores. 0 contraponto se constitui no fato de que a exposição ao risco e à vulnerabilidade potencial ocorrido com inadimplências efetivadas, aumenta.

A habilidade do sistema financeiro também está em ofertar crédito na medida certa e dispor de mecanismos que assegurem o correto provisionamento de reservas e recursos, para fases complicadas de uma economia, em especial para recessões profundas e prolongadas.

\section{DETERMINANTES MACROECONÔMICOS DA INADIMPLÊNCIA.}

\section{ELEMENTOS INTRODUTÓRIOS}

A macroeconomia organiza, analisa e pensa grandes estruturas agregadas da economia, para estabilizar e harmonizar seus movimentos e interações no tempo. A ela cabe lidar com a Economia de ordem maior, para assegurar que ocorra o crescimento econômico com desenvolvimento; uma estabilidade de preços com eficaz combate à inflação; e a formação de reservas internacionais, oriundas de políticas comerciais internacionais que tornem 
preferencialmente superavitárias tanto as contas da balança de Transações Correntes, quanto a conta Capital, dos movimentos de Investimentos Diretos e valores líquidos entre empréstimos e financiamentos e créditos ao exterior.

Com vistas a acertar este tripé, praticam-se políticas econômicas, que precisam de atualidade e transversalidade com outras áreas, na medida em que os gostos, preferências e informações dos consumidores se modificam; o tamanho do mercado cresce e a oferta há de se expandir; a tecnologia gera mudanças marcantes, freqüentemente súbitas, dadas por transformações nas telecomunicações, na Internet, ou na medicina, entre outras; os sistemas político-sociais se aperfeiçoam rumo à democracia e à participação consciente dos direitos dos cidadãos; as nações se associam em blocos comerciais; a autosustentabilidade ganha espaço no trato e comportamento das pessoas e nações; e modificam-se as formas de enxergar os usos da propriedade física e intelectual.

Neste particular, é importante que o assunto econômico se combine com o jurídicolegal, de tal forma que seja estabelecida uma ponte forte entre atividades econômicas e regulamentações, estas previstas para serem realizadas caso preciso judiciáriamente, para fazer os mercados funcionarem consistentemente.

As políticas econômicas, neste âmbito, funcionam freqüentemente mediante a apresentação correta de regras de conduta e procedimentos normatizados, estabelecidos em lei.

E por serem numerosas as políticas, cabe verificar se operam sistêmicamente, com certa lógica para o consumidor, o cidadão, o produtor, o governo estabelecido e o mercado, para que de forma uníssona, também holística, façam funcionar tal e qual uma orquestra bem afinada as medidas que visam atender a demanda agregada, com a mais racional e econômica oferta agregada.

As principais políticas macroeconômicas que estão nas mãos das autoridades instituídas, mormente o Ministério da Economia, neste a Secretaria do Tesouro Nacional ou equivalente, e o Banco Central, são a política monetária; a fiscal; a de preços; a salarial e de custos de fator; a cambial; e a comercial. Combinadas, estas políticas são a força motriz que faz girar a política de rendas e a constituem.

Deste modo, ao analisar-se a inadimplência sob um foco e olhar macroeconômico, cabe ao analista verificar as relações existentes entre o volume presente e futuro de crédito, em face de atrasos e calotes dados neste em termos agregados pelos devedores e consumidores.

Decorre que este é um tema eminentemente associado a política monetária e a política de crédito, com suas associações a políticas de mercados bancários, financeiros e de capitais.

\section{MODELOS MACROECONÔMICOS INTERNACIONAIS}

Yeager (em 1974) desenvolveu um dos primeiros estudos empíricos acerca dos determinantes macroeconômicos explicativos das falências dos consumidores, para os anos 1950-1970 e considerou o crescimento falimentar para cada 100.000 norte-americanos. Ao dispor como única variável explicativa a razão de endividamento sobre o consumo, com uma defasagem semestral, explicou $94 \%$ do crescimento falimentar do período.

Isto é, Yeager mirou e enfatizou o endividamento excessivo das famílias, apontando ao descontrole das contas como o fator explicativo das falências da pessoa física. Em 1983 Sullivan atualizou a pesquisa de Yeager, expandindo a série histórica analisada para 1950- 
1982, confirmou a importância da razão de endividamento sobre consumo nas quebras de pessoas físicas e utilizou o Consumer Sentiment Index-CSI como medida da propensão e vontade em repagar dívidas assumidas. Kowalewski (1982) articula um modelo intertemporal de maximização da função utilidade do consumidor, no qual as curvas de preferência entre o consumo presente e o consumo futuro são sujeitas a uma restrição orçamentária imposta pelos rendimentos presentes e futuros. A variável dependente do modelo é o número de falências per capitã, com dados trimestrais de 1961 - 1979.

Mais recentemente, Fay, Hurst e White (2002) mostram a falência como o resultado de um ato premeditado, discutido e avaliado em família, logo de teor estratégico. Ele não seria o fruto de ocorrências imprevistas, simplesmente, poderia acontecer e em certos casos com perdão parcial de dívidas ou ausência de garantias a receber de volta, beneficiaria os casais endividados. Em 2004 Zywicki segue linha similar, mais comportamentalista, para acentuar que em mais de $90 \%$ dos casos o alto endividamento dos consumidores e os choques financeiros não antecipados são as razões explicativas das falências da pessoa física.

Sumit Agarwal e Chunlin Liu analisam a delinqüência sucedida em cartões de crédito e mostram que o desemprego súbito e localizado, posto que diferenciado por municípios e distritos, afeta profundamente o devedor (Determinants of Credit Card delinquency and Bankruptcy: Macroeconomic factors; 2003). Analisaram 700.000 contas de 1995 em diante nos EUA e perceberam que a atividade econômica diferenciada em termos regionais muda as figuras da inadimplência. Na Flórida, a delinqüência monta a 4,5\%, enquanto em Massachussetts ela cai a 2,5\%, num período analítico de 32 meses.

Uma política liberal em excesso e sem cobranças, "friendly", como apontamos neste estudo e que sucedeu no período 1980 / 2007 de modo crescente, nos EUA, no Canadá e na maior parte da Europa, motivou as pessoas e indivíduos a ambos: o endividamento e o superendividamento.

Ocorreu uma sobreoferta de crédito, para manter a economia aquecida e crescendo; aumentar o bem-estar geral; e aumentar os lucros de curto prazo das instituições financeiras. Mas o fundamental, que é a formatação com lisura e coerência de uma curva de oferta realista, que contemple uma função de liberação de crédito agregado à luz de uma relação de custo e beneficio de longo prazo, essa foi esquecida.

A crise do mercado subprime deus seus sinais iniciais e problemáticos em maio de 2006. E foi encorpando, para comprovar uma gigantesca bolha de crédito imobiliário, dada com base em técnica limitada e voracidade de ganhos altos a curto prazo, substituídos por perdas monumentais estimadas em potenciais 2,7 trilhões de dólares nos EUA, em setembro de 2008.

Como o mercado de crédito é visto por credores e devedores como um sistema integrado e que age operação a operação, o estresse complexo ao qual o sub-segmento de crédito imobiliário foi submetido pode acometer e penalizar, afetar e frear outros subsegmentos. 0 efeito-cadeia e o efeito dominó passam então a aparecer. Como que em série, um segmento pode abalar outro e isto põe em risco a liquidez e a segurança das carteiras de recebíveis dos bancos.

0 ato de liberar crédito em excesso gerou comportamentos não desejáveis, indutores de inadimplência e falência involuntária ou premeditada. Saber como aconteceu e o que gerou o não pagamento, é objeto de análise de crédito caso a caso. Isto se faz nas diretorias de Análise 
de Crédito de cada financeira e banco, per se e para fins de determinação do perfil dos "endividados - não-pagadores".

\section{DETERMINANTES MICROECONÔMICOS DA INADIMPLÊNCIA}

Conforme a Teoria, um indivíduo quererá na essência maximizar a sua função consumo, para desta extrair a mais elevada satisfação, sujeito a uma restrição orçamentária. Caso o indívíduo tenha alguma propensão a poupar, ele dividirá a renda líquida disponível entre consumo e poupança. Quanto maior for a sua propensão a consumir, menor será a sua propensão a poupar. Logo, ele empenhará a maior parte de sua renda a presente, sem maior interesse pelo futuro. E vice - versa, caso um indivíduo tenha alta propensão a poupar, ele aceitará a redução e o sacrifício do consumo presente, para auferir maior renda futura, pois ela na base da poupança primária realizada, será acrescida de juros que aumentarão sua renda futura e sua capacidade de consumo futuro.

Nos países desenvolvidos, nos quais um regime de distribuição de renda possa ser considerado internamente "social e economicamente justo", e nos quais se estimulem mercados de capitais eficientes, é de se esperar que a cultura da poupança seja premiada e incentivada. As instituições financeiras terão um montante de captações estimulante e elevado em relação ao PIB e caso exista estabilidade macroeconômica associada a um sistema de justiça eficiente e correto na essência, com empreendedores motivados em fazerem investimentos, a demanda por capitais estimulará a formação e o fortalecimento do mercado de crédito.

A oferta de crédito estimulará a demanda e o consumidor assumirá empréstimos e financiamentos, na esperança positiva de aumentar seu consumo presente, pago também com créditos da banca e das financeiras, ressarcido a futuro com as rendas permanentes e flutuantes obtidas no emprego e em papéis e ativos remunerados que estão na carteira do investidor, sobretudo.

O indivíduo haverá de estabelecer uma correta medida de endividamento sobre sua renda e capacidade de pagar. Se tomar de menos, assegura pagamentos à banca, por outro lado deixa de consumir e não maximiza necessariamente a sua função consumo e satisfação. Se, pelo contrário, tomar demais, ou ao repactuar créditos o fizer sabendo que assumiu uma "bola de neve" que se forma com o acréscimo de mais juros, e que ficam impagáveis, o risco crescente de inadimplência sucede, e a banca pode ser prejudicada.

0 crédito não pago e visto de forma premedidata com tal, que não será pago pelo tomador, torna-se um crédito delinqüente. Isto explica que na formação do mercado de crédito, uma harmonização de interesses deverá subsidiar a política de liberação e renovação de créditos. Quem toma há de cuidar para maximizar sua satisfação presente e futura, sem sujeitar-se a estresses provocados pela absorção excessiva e errada de créditos.

Na literatura moderna e corrente, vamos acorrer ao UK Debt Help \& Insolvency Helpline, que estuda o assunto e possui vasta experiência interativa on-line com pessoas inadimplentes, insolventes e falidas, o que lhe reporta consistentes estatísticas e um banco de dados importante sobre o assunto (UK - DH\&IH, 2008).

No Brasil, os levantamentos, pesquisas e as análises da IBCI - Institutional Business Consultoria Internacional; da SERASA - Experian Company; do Instituto de Economia Gastão Vidigal, da Associação Comercial de São Paulo - ACSP, onde o Professor Marcel Domingos Solimeu atua e dispõe provavelmente das mais longas séries temporais atinentes a falências e 
concordatas no Brasil; e o Serviço Central de Proteção ao Crédito - SCPC entre outros, merecem atenção e destaque.

As variáveis, que levantamos exaustivamente ao utilizar as fontes anteriormente mencionadas, poderão mediante os levantamentos feitos em pesquisas atinentes ao perfil dos inadimplentes mostrar a real importância de cada variável no contexto brasileiro. Quanto maior for o percentual registrado de respostas para uma variável, causa ou característica, fatores estes que combinados geram o perfil do inadimplente, tanto mais caberá ser atento a ele e sua variável, porque maior será a probabilidade de ocorrência de uma inadimplência.

As principais razões apontadas e alegadas para a quebra são as seguintes, no caso das pessoas físicas e servem de indicadores antecedentes para potenciais problemas de não pagamento de créditos assumidos:

- divórcio ou separação;

- maternidade solteira;

- doença;

- inabilitação e perda de direitos de motorista;

- acidentes que inabilitam;

- desemprego;

- mau emprego, de baixa ou menor renda;

- perda de poder aquisitivo salarial com o passar do temo;

- perda de poder aquisitivo de aposentadorias e pensões com o passar do tempo;

- quebra de contrato e promessas no trabalho ou emprego;

- atrasos no pagamento de salários;

- atrasos no pagamento de contratos;

- financiamento de carro;

- financiamento de eletrodomésticos;

- confusão entre contas pessoais e de microempresário;

- tentativa de empreendorismo fracassado;

- porque a experiência de fazer um projeto de empresa que afunda isola, e você se sente só, sem ter com quem falar;

- porque no lugar de me orientar, o credor não foi sincero, podendo ver e orientar mais, fez vista grossa aos acontecimentos;

- porque é do comportamento do credor querer afirmar que está tudo bem, mesmo quando está mal, como sinal de confiança e para não perder o cliente se a situação melhorar;

- porque as ameaças de pagar e ressarcir, descontrolaram a pessoa;

- investimento em negócio próprio, acima da capacidade de sustentação;

- mudança nas regras de bonificação em empresas com dificuldades;

- mudança nas regras de pagamento de rendas flutuantes, como horas - aula e pesquisas;

- mudança das regras de mercado, regulamentação que quebra o pequeno empresário;

- descontrole dos gastos;

- ter aceito ser fiador ou avalista;

- ter "emprestado" o nome;

- ter acumulado dívidas fiscais, declaradas;

- ter sido flagrado pela malha fina, por dívidas fiscais, declaradas e não declaradas;

- taxas de juros;

- repactuação com indexador maior que o utilizado para ajustar salários, aposentadorias ou pensões;

- desinteresse em continuar pagando, porque o produto caducou, obsoleto; 
- cálculo e projeção errada do futuro pessoal, em relação à formação de renda, patrimônio, salário e afins;

- ter caído no "conto do vigário", o crédito parecia "barato";

- ter acreditado no chefe, na empresa e na promoção prometida e não cumprida;

- porque arriscou acima do devido, consciente;

- porque foi induzido a assumir mais risco, ante uma facilidade de crédito que anuvia a curto prazo - "efeito relax financeiro";

- porque apostou que a empresa, financeira ou banco quebraria antes, logo a massa falida iria ao PROER e o devedor seria perdoado;

- apostas (apostador viciado) em bicho, loterias, cassinos e outras;

- sofre de "doença crônica de compra em shoppings";

- sofreu assalto;

- sofreu assalto em banco, loja;

- sofreu seqüestro - relâmpago com pagamento de resgate;

- sofreu seqüestro complexo ou parente e resgatou caro;

- sofreu achaque de bandidos;

- sofreu achaque de fiscais;

- subitamente, virou gastador;

- não tinha seguro, a casa queimou; o carro foi roubado ou bateu no poste;

- não tinha seguro, foi processado por vítima;

- furacões, raios, trovões, granizo, inundações e outros acidentes maiores da natureza;

- outras razões alegadas.

Da longa lista que se levantou anteriormente, claro está que certas variáveis possuem peso bem maior do que outras. Existem variáveis literalmente acidentais, de causa maior, como as atribuídas aos fenômenos da natureza, como vendavais, furacões e inundações, que nem sempre se repetem e independem da vontade humana. Outras variáveis, pela sua natureza, são associáveis a fenômenos de tomada de decisão pessoal, como o ato de tomar ou não um empréstimo, a dada taxa de juros de mercado.

Portanto, em pesquisas deste gênero, após a correta filtragem, é de se esperar que surjam poucas, mas estatisticamente robustas, variáveis independentes explicativas das inadimplências.

\section{COMPARAÇÃO DA INADIMPLÊNCIA ENTRE PAÍSES}

\section{A INADIMPLÊNCIA E A INSOLVÊNCIA ENTRE PAÍSES}

Esta seção visa descrever os níveis de insolvência individual numa perspectiva comparativa internacional, para países selecionados e com ótica de longo prazo.

Os desenvolvimentos e as evoluções da insolvência são interpretadas com base e referência nas características, no perfil aparente e na existência de regras estatutárias de insolvência.

Ao estudar-se e comparar-se a estatística em termos internacionais, os dados disponíveis precisam ser normalizados, para que haja condições de se fazer comparações adequadas. Trata-se de uma questão de comparabilidade e entendimento de proporções, posto que é preciso comparar o fenômeno da insolvência e da inadimplência para países que possuem populações de tamanhos bem variados.

Então, não é o valor absoluto registrado de inadimplementos per-se, que interessa, mas sim a quantidade de pessoas que entram em colapso financeiro, para uma dada quantia de 
membros da população.

Esta normalização há de considerar também as especificidades de cada país, onde se incluem o tamanho da população; o número de empresas atuantes; o tamanho médio das empresas, classificadas por número de empregados registrados; e a população economicamente ativa. Ao longo desta seção, o número de insolvências será relacionado a um milhão de habitantes em todos os países considerados.

A amostra que apresentou condições de ser estudada se compôs dos seguintes países: Holanda; Grã-Bretanha; Suécia; Alemanha; Canadá; Estados Unidos da América (EUA); Austrália e Brasil. Este grupo pode ser considerado bem qualificado, porquanto dispõe de quatro países europeus ricos e altamente desenvolvidos cujo IDH - índice de

Desenvolvimento Humano suplanta o valor 0,9, o mesmo sucedendo com as duas mais ricas economias do subcontinente norte-americano e com a continental Austrália (cf. : Kasznar, Istvan; in: Financeiro; 2006).

Pode-se distinguir claramente três grupos distintos de nações, no que diz respeito à evolução recente de sua população insolvente, a saber: aqueles nos quais a insolvência relativa da população cresce positivamente, sobre uma base relativamente pequena, mas rápido, constituída da Holanda; da Grã-Bretanha; da Alemanha; e da Austrália - que chamaremos de Grupo A. O grupo B, formado pela Suécia, cujo desempenho aparenta a maior constância, estabilidade e regularidade, sem maiores sobressaltos. E o Grupo C, formado pelos Estados Unidos e Canadá, onde a insolvência cresce para uma proporção alta da população e as taxas dos anos recentes são maiores que as registradas no passado.

Neste particular, a taxa de insolvência geral, que inclui dados para indivíduos e negócios, entre 1980 e 2005, é de 5,9\% para os EUA e 4,3\% para o Canadá, conforme Osterkamp (em: Insolvency in selected OECD countries; R. O.)

QUADR0 3: Total de Insolvencias (Negócios e Individual) - 2000 / 2005 em Países selecionados - Dice Report 1/2006

\begin{tabular}{|l|c|c|c|c|c|c|c|}
\hline Ano & HOLANDA & GRÄ BRETANHA & ALEMANHA & SUÉCIA & CANADÁ & USA & AUSTRÁLIA \\
\hline 2000 & 302 & 884 & 528 & 871 & 3150 & 4540 & 1208 \\
\hline 2001 & 391 & 890 & 576 & 877 & 3175 & 5160 & 1216 \\
\hline 2002 & 436 & 899 & 745 & 868 & 3142 & 5430 & 1223 \\
\hline 2003 & 487 & 952 & 1008 & 860 & 3171 & 5720 & 1190 \\
\hline 2004 & 546 & 1006 & 1415 & 872 & 3423 & 5510 & 1199 \\
\hline 2005 & 610 & 1147 & 1907 & 858 & 3478 & 6480 & 1220 \\
\hline
\end{tabular}

Fonte de Cálculos: IBCI - Institutional Business Consultoria Internacional Ltda. Origem: Osterkamp / OCDE 
GRÁFICO 2: Total de insolvências (negócios e individual) - 2000/2005 em países selecionados - Dice report $1 / 2006$

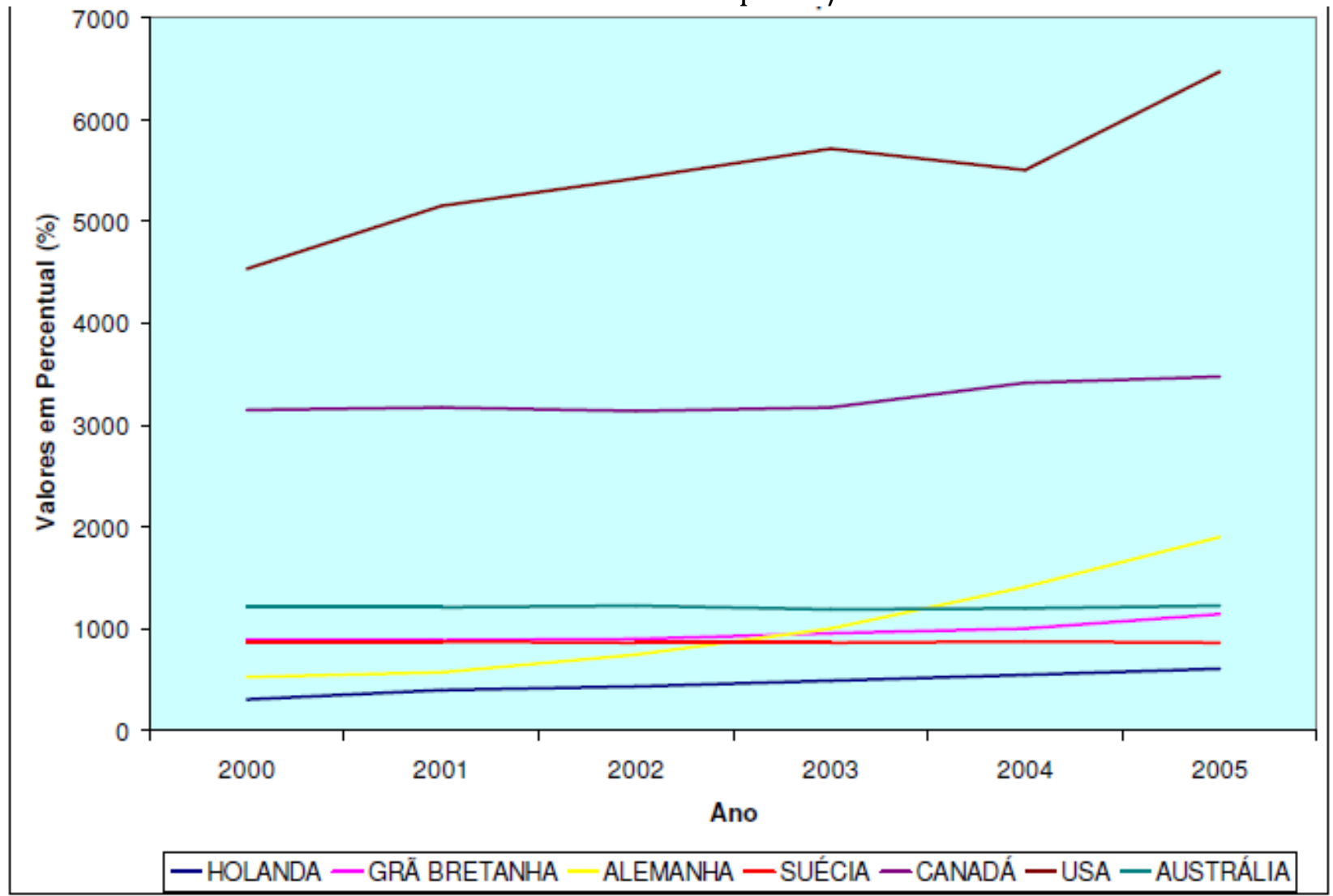

Na dinâmica internacional, o fator principal que parece conduzir ao crescimento positivo da dinâmica das insolvências é a insolvência individual, pessoal. Logo, aquela que se associa a desemprego e perda de renda. As taxas geométricas de crescimento dos indivíduos são bem mais altas que as taxas totais verificadas, logo as empresas tendem a ser menos insolventes, porque controlam melhor seus fluxos de caixa e possuem especialistas em finanças que põem em ordem as suas contas.

A insolvência na Alemanha cresceu ao assustador ritmo médio de $13 \%$ ao ano; da Holanda a 11,3\%; e da Grã-Bretanha a 8,0\%, entre 1980-2005. A maior proporção de indivíduos insolventes sobre a população total é com primazia absoluta dos EUA e a seguir, do Canadá, embora menor. Em que pese a retomada da insolvência recente na Alemanha e na GrãBretanha, a razão de insolvências entre os países tende negativamente aos EUA: para cada 6.200 insolvências americanas registradas em 2005, havia aproximadamente 1.110 na Alemanha e na Grã-Bretanha, ou seja, a insolvência nos EUA foi 5,59 vezes maior que naqueles países.

Esta proporção elevada sugere e fornece evidências para um descontrole e um superendividamento nas contas e dívidas dos norte-americanos. Isto é, passaram a financiar seu consumo com créditos diversos, como os cartões de crédito, o crédito direto ao consumidor, os financiamentos a veículos e imóveis e afins, e não tiveram condições de fazer poupança, provisionamentos, com os fins de cobrir seus passivos.

Desta forma, a crise da subprime e dos títulos hipotecários era visível e se aproximava havia 
pelo menos sete anos, desde 2001, quando então os indicadores de insolvência subiram com persistência e sem parar.

O país que possui o menor índice geral de insolvência individual é a Suécia. E os indicadores recentes mostram redução dessa insolvência, em princípio porque a legislação é severa e firme, cobrando do consumidor e devedor o devido e porque o nível educacional e cultural dos suecos permitiu elevar a níveis inéditos a disciplina orçamentária doméstica.

Na Alemanha, acontece um fenômeno recente, de retomada explosiva das insolvências do ano 2001 em diante. E ela se deve em grande arte a reformas legais. Em 1999, introduziu-se a possibilidade de cancelamento de dívidas para indivíduos insolventes que não tivessem microempresas e afins. Como reação imediata, a insolvência disparou e mais do que dobrou em menos de dois anos, saltando de 202 insolvências por milhão em 2001, para 617 em 2002 e 825 no ano 2003.

A unificação da Alemanha inicia-se com a queda do muro de Berlim, em 1989. Implicou na absorção da depauperada população da Alemanha Oriental, que foi habituando-se às vantagens capitalistas e consumistas do mundo ocidental. Mesmo após 20 anos de unificação, persistem os desafios de integrar pessoas que não possuem mais trabalho especializado e de valor, de tal sorte que ficam sujeitas a empregos informais, voláteis e de baixa renda.

Desta forma, para explicar-se a tendência geral de crescimento positivo na insolvência das pessoas físicas, dois fatores se mostram preponderantes. Primeiro, as novas legislações de insolvência permitem o descarregamento das dívidas e sua eliminação contábil, como uma perda (a net loss is debt dischargeable). E segundo, dívidas de consumidores, majoritariamente não asseguradas crescem por causa da desregulamentação legal dos mercados de capitais.

Desde 1984, uma numerosa onda de leis sobre inadimplência e insolvência sucedeu. Nesse ano, houve reformas nos EUA e na Dinamarca. Em 1994, novamente os EUA reforçaram as suas reformas, com países europeus independente modernizando as suas legislações, como Áustria, Alemanha e Suécia. Em 1997 o Canadá e a Holanda fizeram suas mudanças legais e a Alemanha liberou sua dura legislação em 1999 e 2001. Novamente os EUA arejaram em 2005 sua legislação.

Em praticamente todas estas reformas, um denominador comum de valores pode ser identificado, a saber: a legislação é favorável e amiga dos devedores. Estes são favorecidos e tratados com cada vez maior probabilidade de perdão de dívidas.

A exceção a esta tendência acontece tardiamente nos EUA e no Canadá. Nos EUA, após a disparada altista das insolvências, a reforma de 2005 procura cobrar de fato as dívidas e recuperar pelo patrimônio disponível os passivos assumidos pelos indivíduos e famílias.

No Canadá, em 2003 o número de casos de insolvência dos consumidores chegou a 100.745, o que equivale a 4,1 casos para cada 1.000 canadenses que possuem acima de 18 anos.

O envelhecimento da população européia acarretou uma dependência significativa dos aposentados e pensionistas pela Previdência, os sistemas de Assistência Social e pelas políticas de reajuste de aposentadorias e pensões. Em geral, os reajustes são menores que a inflação, corroendo o poder aquisitivo dos orçamentos, que se apequenam em termos reais, o que leva numerosos membros da terceira idade à quebra. E entre as suas principais despesas, ressaltam-se os gastos com remédios e saúde. Quando estes disparam no orçamento familiar 
ou individual e este não possui cobertura de seguro, nem há entrega de remédio pela secretaria de saúde municipal, aumenta a probabilidade de insolvência (Kilborn, J.).

Portanto, após a experiência dos anos 1984 - 2005, quando a declaração de insolvência das pessoas físicas disparou, registram-se duas tendências: volta-se atrás na legislação amiga, para endurecê-la novamente; e legislações excessivamente restritivas, que podem inviabilizar e estigmatizar socialmente os devedores são modificadas, para viabilizarem e darem nova chance ao devedor, trazendo-o de volta ao circuito sócioeconômico.

\section{O COMPORTAMENTO OPORTUNÍSTICO DO DEVEDOR}

Faz sentido que o consumidor, quando grande devedor, em relação à sua renda, se pergunte se deve relaxar moral e eticamente quando muda a Lei e esta acena com menos punições ou penas ao ato de atrasar ou não pagar dívidas.

Talvez ele saiba e esteja consciente de que a dívida há de ser quitada, contudo, para novas regulamentações, ele age conforme a relação de custo / benefício que pode tirar de cada nova situação. Assim, ele se move conforme as oportunidades.

Se a punição de não pagar diminui, a propensão do consumidor em não pagar aumenta. E vice - versa, se a punição aumentar, sua propensão em calotear diminui, isto é, a propensão a pagar a dívida aumenta.

Portanto, além do desemprego, que corta a renda salarial do indivíduo a zero; do mau emprego, do subemprego ou do emprego temporário, que rendem pouco e abaixo do potencial do indivíduo; da tendência ao aumento da taxa de desemprego; das taxas de juros crescentes; e da ascensão na proporção entre dívida e renda presente e futura do consumidor, é determinante a mudança na legislação, para explicar as recentes crises de inadimplência e de insolvência, no mundo do crédito da pessoa física.

O superendividamento das famílias também é causado pela sobreoferta de crédito por alguns bancos, que aceitam mais riscos e se perfilam como mais agressivos, para conquistar "mais clientes". Contudo, nem sempre os clientes são "efetivos bons pagadores", podendo ser "potenciais clientes, maus pagadores, sem potencial de ressarcimento de dívidas".

Conforme Zywicky (2005) e Osterkamp (2006), "os indivíduos aparentam estar escolhendo crescentemente entre assumir e declarar a bancarrota como uma resposta ao desequilíbrio financeiro, em vez de reduzir o gasto ou gerar poupanças para evitar a bancarrota".

\section{POSSÍVEIS POLÍTICAS MACRO, PARA A NEGOCIAÇÃO DE CRÉDITOS INADIMPLENTES.}

Na Suécia, a 7 de janeiro de 1999 o governo decidiu os termos de referência sobre as políticas de defesa e de promoção do consumidor para o próximo século XXI. Entre as propostas mais importantes para favorecer o consumidor no mercado e aumentar a atenção em prol da defesa de seus interesses, figuram as seguintes medidas, ratificadas no Relatório Final de abril de 2001 (Sweden, Annual Report on CPD), a saber:

- A criação de centros de aconselhamento do consumidor em todos os distritos, obrigatoriamente;

- 0 estabelecimento de um Ministério de Assuntos de Consumo, para esclarecer melhor as atividades governamentais a favor do consumidor;

- Oferta de mais dinheiro para as organizações especializadas em consumidores; 
- Reforço de equipes de conselheiros em gestão de passivos, na área dos serviços financeiros;

- O saber do consumidor e seus direitos, uma nova disciplina escolar;

- A extensão do Ato de serviços ao consumidor (CSA) às áreas de serviços ainda sem regulamentação; e a...

- Adoção de regras prévias de informação sobre quaisquer bens e serviços oferecidos.

\section{CONCLUSÕES ESTRATÉGICAS.}

Crises bancárias no mundo foram precedidas por uma oferta de crédito expansiva, real e agressiva. Uma rápida e continuada deterioração do ambiente macroeconômico, sem a adoção de medidas firmes e vigorosas, aprofunda as crises e aumenta as perdas da sociedade e do sistema bancário.

No Brasil, de 2005 em diante, experimenta-se com uma certa sensação de satisfação a expansão vigorosa do crédito ao consumidor e a capacidade do Estado sustentar com empréstimos a retomada maior do crescimento do PIB. Contudo, toda expansão possui seus limites e mais vale o crescimento seguro e regular, que o crescimento explosivo e de fôlego curto, seguido de operações de rescaldo às pessoas físicas e empresas e de socorros bancários, que em sua dimensão fiscal, mediante impostos, acabam saindo dos bolsos do contribuinte.

\section{BIBLIOGRAFIA}

ABRADEE - Associação Brasileira de Distribuidores de Energia Elétrica; Resultado Consolidado da Inadimplência do Setor de Distribuição; 3T06; 2006.

ACREFI; Revista Financeiro, série de 2004 a maio de 2008; www.acrefi.org.br; 2008.

Banco Central do Brasil; Relatório Anual dos anos 1975 a 2007;

Banco Central do Brasil; Relatório de Economia Bancária e Crédito - 2007; texto técnico: Porque o volume de empréstimo consignado no setor privado é baixo? Qual a solução? Por Tson Chu, Victorio; Lundberg, Eduardo Luis e Takeda Tony.

Banco Central do Brasil; Relatório de Estabilidade Financeira; Volume 7 - número 1; Maio de 2008.

Borges Matias, Alberto; Inadimplência e Insolvência no Brasil; Análise setorial; INEPAD Instituto de Ensino e Pesquisa em Administração; em Financeiro, A revista do crédito; anos 1 a 6 , nos 1 a 53 .

Borges Matias, Alberto; Banco de Dados por INEPAD - Instituto de Ensino e Pesquisa em Administração; em Financeiro, A revista do crédito; anos 1 a 6, nos 1 a 53.

Com alta do aluguel, número de ações de denúncia vazia aumenta $40 \%$ em SP; www.imobilien.com.br; julho 2008.

Conjuntura Econômica; vol. 40 a 62, nos 1 a 12; Fundação Getulio Vargas.

Fay, Scott; Hurst, Eric e White, Michelle J.; em The Household Bankruptcy decision; ERA American Economic Review; vol. 92; n. 3; june 2002. 
FEBRABAN; Melhores Práticas na Gestão do Risco operacional; Grupo de Trabalho de melhores práticas, coordenação de Terence Augusto Guimarães et alii; São Paulo; março de 2006.

Fraser, Donald \& Rose, Peter S.; Financial institutions and markets in a changing world; third edition; Business publications, Inc.; 1987.

Fuhrer, Jeffrey C. \& Schuh, Scott; Beyond Shocks: what causes business cycles?; Conference Series n. 42,; Federal Reserve Bank of Boston; June, 1998.

Inadimplência amedronta o Ensino Privado; www.universia.com.br; 2008.

Instituto Akatú; O Consumo Consciente do Dinheiro e do Crédito; www.akatu.org.br; 2008.

Instituto Akatú, pelo Consumo Consciente; Responsabilidade Social das Empresas; Percepção do Consumidor Brasileiro; www.akatu.org.br; 2005.

Instituto Ethos; Empresas de Responsabilidade Social; www.ethos.org.br; 2008.

Kasznar, Istvan Karoly; em Falências e Concordatas de Empresas - Modelos teóricos e Estudos Empíricos - 1978 - 1982/1987; Edição do SBERJ - Sindicato dos bancos do Estado do Rio de Janeiro; novembro 1987.

Kasznar, Istvan Karoly; em Financeiro, A revista do crédito; anos 2 a 6, nos 16 a 53.

Kasznar, Istvan Karoly; Estresse empresarial no Brasil e a nova Lei de Falência e Recuperação de Empresas; em Recuperação de Empresas; organizadora Fátima Bayma de Oliveira; Pearson Prentice Hall; 2006.

Kasznar, Istvan Karoly; 0 índice de desenvolvimento social e humano no Brasil; Financeiro, A Revista do Crédito; ano 4; n. 33; mar. 2006.

Kasznar, Istvan Karoly; As 10 medidas principais do bom tomador de crédito; ACREFI; www.acrefi.org.br; 2005.

Kilborn, Jason; Comparative Cause and Effect: Consumer Insolvency and the eroding social safety net; John Marshall Law School; Columbia Journal of European Law; vol. 14; n. 3; 2008.

Kilborn, Jason; Behavioral Economics, Overindebtedness \& Comparative Consumer Bankruptcy; John Marshall Law School; Columbia Journal of European Law; vol. 22; 2005.

Kowalewski, Kim J.; Personal Bankruptcy: Theory and evidence; Economic Review; Federal Reserve Bank of Cleveland; vol. 18; n.2; spring 1982.

IBCCA - Instituto Brasileiro de Contabilidade e Ciências Atuariais; dados de Cargas Fiscais e contribuição tributária; anos 2000 / 2007.

IBCI - Institutional Business Consultoria Internacional - Análise dos fatores determinantes de Concordatas e Falências no Brasil - 2000-2006; mimeo. Depto. Pesquisas. Vol 658; www.ibci.com.br; 2006.

IBCI - Institutional Business Consultoria Internacional - Modelos de previsão de falências e concordatas: da ADM às redes neurais e à Teoria do caos na prática; mimeo. Depto Pesquisas. 
Vol 642; www.ibci.com.br ; 2005.

IBCI - Institutional Business Consultoria Internacional - Hot spot zones do crédito pessoa física, na indústria automobilística e do financiamento de veículos; mimeo. Depto Pesquisas. Vol.611; www.ibci.com.br; 2005.

Inadimplência: Como Evitar e Resolver; Saiba Mais; Orientação Empresarial do SEBRAE; Sandra Regina Bruno Florentini; www.sebrae.com.br; 2008.

Moreira, Célia; Perfil do inadimplente sob juro alto; SCPC e Jucesp; em Panorama Brasil; $13 / 03 / 2002$.

Osterkamp, Rigmar; Insolvency in selected OECD countries: outcomes and regulations; CESifo DICE Report; pgs. 27-33; 1 / 2006.

O Observador - Brasil 2008; CETELEM - BNP PARISBAS; 2007 e 2008.

Ruth, George E.; Empréstimos a pessoas jurídicas; Política e Desenvolvimento de educação; ATP - ASBACE Tecnologia e Produtos; ABA - FLB - IBCB; 1991.

Savioli, Adalberto; em: ACREFI promove seminário para discutir novos mecanismos de cobrança; Financeiro, A Revista do Crédito; ano 5; n. 48; out-nov / 2007.

Schrickel, Wolfgang Kurt; Análise de Crédito: concessão e gerência de empréstimos; São Paulo; Atlas; 1994.

SERASA - Na Experian Company; Inadimplência do consumidor aumenta 6,9\%; www.endividado.com.br; 2008.

Sodré, Érico Quirino Ferreira; em: Crescimento das vendas: Natal feliz; Financeiro, A Revista do Crédito; ano 2; n. 19; nov. / 2004.

Soweto, Adex; Factors that may increase personal bankruptcy; Ezine articles; www.ezinearticles.com; 2008.

Sugato, Chakravarty \& Eun Young Rhee; Factors affecting na Individual's Bankruptcy Filing Decision; Purdue University; 1999.

Sullivan, A. Sharlene; Economic factors associated with personal credit bankruptcy; Credit Research Center; Purdue University; 1983.

Sumit, Agarwal \& Chunlin Liu; Determinants of Credit Card delinquency and Bankruptcy: Macroeconomic factors; Journal of Economics and Finance; volume 27; number 1; spring 2003.

Sweden, Annual Report on Consumer Policy Developments; www.oecd.org/dataoecd/35/50 ; 2000.

UK - Debt Help \& Insolvency Helpline; www.insolvencyhelpline.co.uk ; 2008.

Un modèle macroeconomique d'analyse et de prévision de l'insolvabilité commerciale ET des consommateurs au Canadá; Bureau du surintendant; www.strategis.ic.gc.ca . 
What is meant by insolvency?; em Consumer Wiki - Dealing with debt: Insolvency; www.consumerwiki.co.uk .

Yeager, Robert; Personal Bankruptcy and Economic Stability; Southern Economic Journal; vol. 41; n. 01; 1974.

Zywicki, Todd J.; Institutions, Incentives and Consumer Bankruptcy Reform; Law and Economics Working Paper Series; 05-07, George Mason University Law School. 